\title{
Construcció i aprofitament didàctic del coet d'aigua
}

\author{
Àngel Luis Torres Climent (angeltorresfa@yahoo.es) IES Joanot Martorell d'Elx (Alacant) \\ Tomás José Martínez Sempere (tomasjms@gmail.com) Escola d'adults La Llotja d'Elx (Alacant)
}

El present treball constitueix una proposta de construcció i llancament d'un coet d'aiqua i l'estudi experimental del tir parabòlic del mateix. El treball està diriqit a l'alumnat de $1^{r}$ Batxillerat o $4^{t} d^{\prime}$ Educació Secundària de Física i Química i aporta material didàctic perquè el professorat pugui aprofitar aquest atractiu dispositiu.

Paraules clau: Coet d'aigua, tir parabòlic, abast, tercer principi de la dinàmica.

This paper is a proposal to build, launch and experimental study of oblique shot of a water rocket. The work is aimed at students of Secondary Education in Physics and Chemistry and provides educational materials for teachers to take advantage of this attractive device.

Key words: Water Rocket, parabolic shot, scope, third principle of dynamics.

\section{INTRODUCCIÓ}

Sabem que un coet d'aigua és una ampolla de plàstic, parcialment omple d'aigua, en la qual s'introdueix aire a pressió per després deixar que fuita per un orifici de sortida provocant la impulsió del coet. El coet d'aigua és un dispositiu conegut i utilitzat per professors en classes i demostracions. Nosaltres pensarem que podia resultar atractiu $\mathrm{i}$ motivador el presentar als alumnes un problema real amb un plantejament que fos més enllà de la simple demostració i els portés a seguir un mètode científic per poder resoldre el repte plantejat. El coet propulsat per aigua es basa en el mateix principi físic que un autèntic coet espacial: la tercera llei de Newton. Són moltes les demostracions de llançaments que es poden trobar en Internet (veure llistat en bibliografia). És destacable el treball de Nobuaki (2008) on es desenvolupen amb profunditat i rigor diferents aspectes del coet d'aigua. Pot resultar útil aportar una proposta concreta de treball per als alumnes tal com es fa en el treball de Martínez (2008) on s'estudia la trajectòria del coet d'aigua, més enllà de les simples demostracions de llançaments.

\section{EXPERIÈNCIA}

L'experiència que descrivim es va dur a terme amb 25 alumnes de $1^{r}$ de Batxillerat de l'assignatura de Física i Química (assignatura única de 4 hores setmanals a la Comunitat Valenciana) de I'IES Joanot Martorell d'Elx durant el tercer trimestre del curs 2012 / 13. Els objectius que ens marcàrem foren els següents:

- Per als alumnes: Realitzar un treball collaboratiu de cerca de materials, disseny, construcció del coet, presa de dades, etc i aplicar el mètode científic incloent l'elaboració d'hipòtesis i la contrastació de les mateixes prenent mesures, exercint un adequat control de variables.

- Per als professors: Interessar a l'alumnat cap a l'estudi de la física com a ciència que permet abordar situacions molt reals, més enllà dels problemes de pissarra.

\section{Organització de l'experiència}

1aㅡ Fase: Introducció i construcció del coet. 
- S'explica com construir un coet d'aigua i es resolen els dubtes. Es visiona a l'aula un vídeo propi disponible en [1] i es proporciona un guió per a la construcció del coet. Es formen grups de 4 o 5 alumnes. Temps aproximat: 1 sessió de classe.

- Construcció del coet a l'aula.. En la figura 1 es mostren detalls d'aquest treball a l'aula.

- Temps aproximat: 2 sessions de classe.

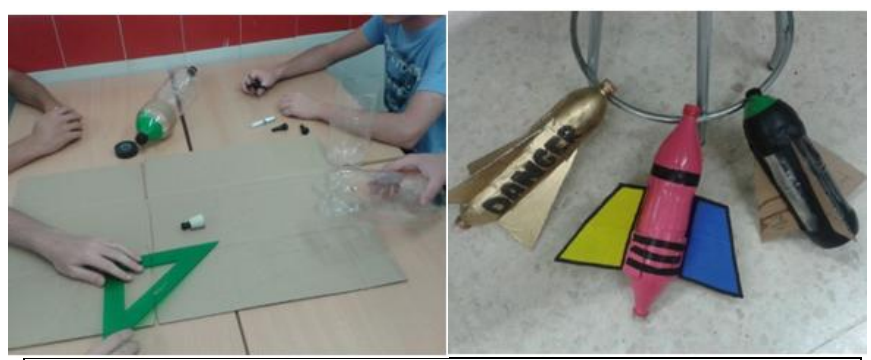

Figura 1. Construcció a l'aula i alguns resultats finals.

\section{2믈 Fase: Recerca i llançaments.}

- Es resolen unes activitats prèvies. Temps aproximat: 1 sessió.

- Recerca. Llançaments, presa de dades, discussió de resultats i conclusions.

- Temps aproximat: 4 sessions.

\section{Guió per a l'alumne per a la cons- trucció del coet}

\section{Material:}

- Aigua

- Ampolles 2 L llises (2)

- Cartró

- Cinta adhesiva

- Corda (50 m)

- Inflador amb manòmetre

- Sorra o plastilina

- Suports de laboratori

- Tap de suro o goma

- Tisores

- Vàlvula

Prenem una ampolla de $2 \mathrm{~L}$ de refresc i tallem la seva part superior a l'altura on comença a estrènyer-se. Aquesta part servirà per introduir un contrapès (sorra, plastilina...) i anirà subjecta amb cinta adhesiva a la part posterior d'una altra ampolla de 2L. (figura 2).

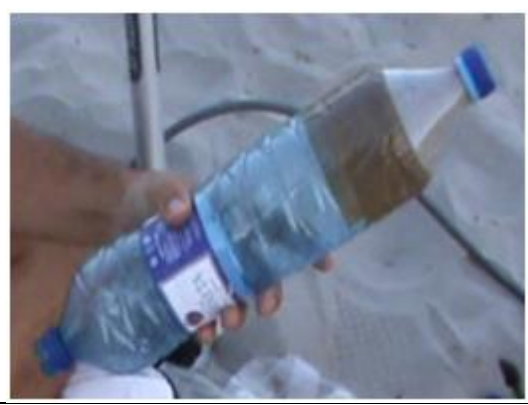

Figura 2. Cos principal del coet

Seguidament construïm uns alerons que subjectarem en la superfície del coet (figura 3).

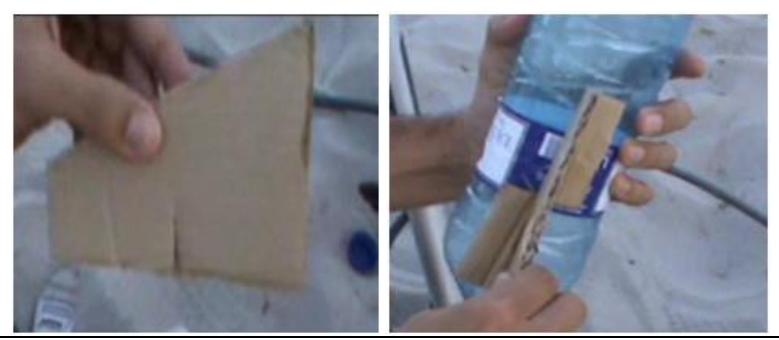

Figura 3. Forma i disposició dels alerons

Perforem el tap a la mesura de la vàlvula. Inserim la vàlvula, segellant-la en cas necessari amb cola per evitar pèrdues de pressió (normalment amb el tap de goma no és necessari). Omplim l'ampolla amb l'aigua, aproximadament un terç del seu volum. Tapem amb el tap i connectem la vàlvula a la bomba (figura 4)
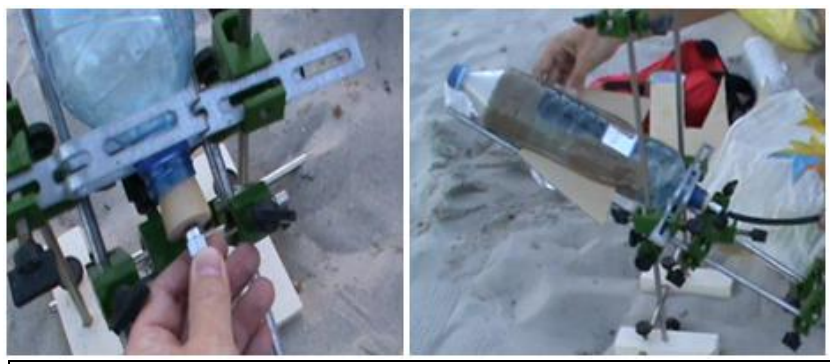

Figura 4. Detall del tap i disposició del coet

Atès que és molt important retenir el coet i el tap fins al valor de la pressió a la qual volem realitzar el llançament utilitzarem un mecanisme de retenció com el que es mostra en la figura 5. 


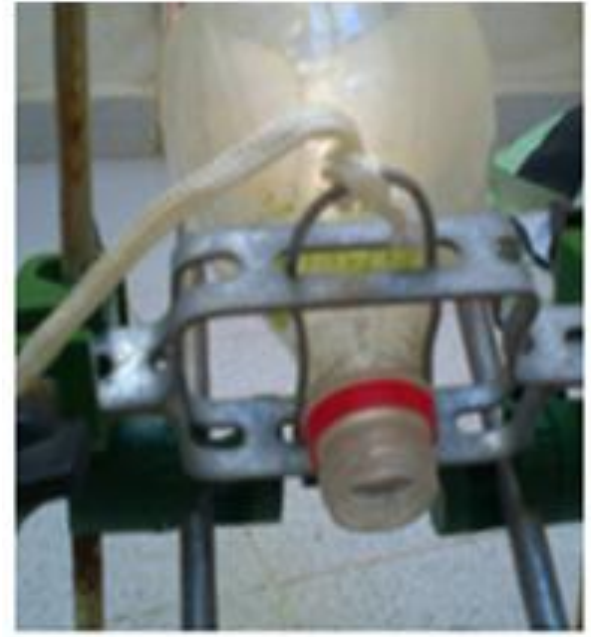

Figura 5. Mecanisme de retenció

S'acciona la bomba fins a arribar a la pressió desitjada, alliberant llavors el dispositiu de retenció de l'ampolla. En aquest moment l'aigua surt disparada cap enrere i el coet cap endavant (figura 6). En l'adreça [2] es poden veure alguns dels Ilançaments realitzats amb els nostres alumnes.

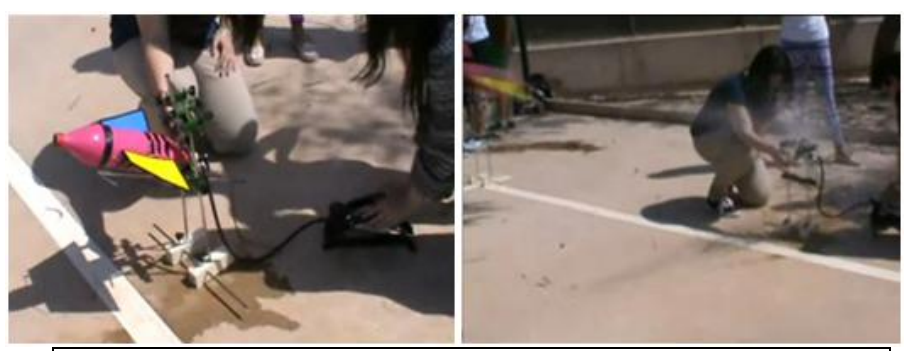

Figura 6. Detall d'un Ilançament

\section{Activitats prèvies}

S'han inclòs en cursiva algunes anotacions que poden resultar útils al professorat que vulgui reproduir l'experiència.

\section{a) Descriu detalladament per què surt propulsat el coet.}

L'alumne hauria de proposar algun dels principis següents: tercer principi de la dinàmica, conservació de la quantitat de moviment o principi de conservació de l'energia. El coet és propulsat cap a endavant per una força que és parella de la que impulsa en sentit contrari a l'aigua (figura 7). Si els alumnes apliquen un raonament energètic haurien d'indicar que el coet surt propulsat perquè li hem transferit energia amb el nostre treball, energia potencial emmagatzemada inicialment en l'aire a pressió i que es transforma en energia cinètica del coet propulsat, de l'aigua i de l'aire expulsats en el llançament.

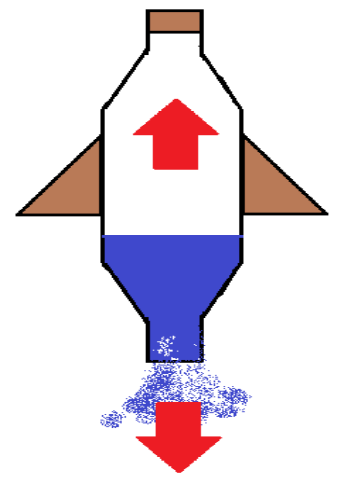

Figura 7. $3^{\text {a }}$ Ilei de la dinàmica en el coet d'aigua

b) Creus que si no hagués aire fora, a l'exterior del coet, podria volar? ¿Podria funcionar el nostre coet sense aigua?

És important que els alumnes entenguin que la interacció es dóna entre la matèria que és extreta $i$ el coet. No és l'aire extern sinó l'aire que hi havia dins el que empeny el coet i, per tant, podria volar en absència d'atmosfera, com fan els coets espacials. L'aigua té una important missió d'alentir el procés d'expulsió de l'aire, fent que la força actuï durant més temps aconseguint-se major impuls i velocitat.

c) Dibuixa les forces que actuen sobre el coet en els següents punts de la seva trajectòria (figura 8).

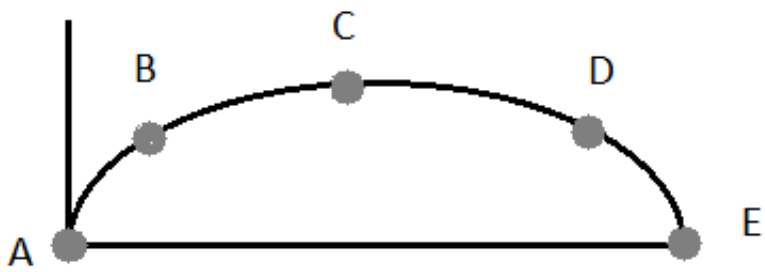

Figura 8: A, Instant de l'enlairament, B Coet alliberant aigua, C, D, E el coet ja no allibera aigua

Els alumnes haurien de dibuixar un esquema que inclogués la força pes i la força d'impulsió, només mentre el coet està expulsant aigua. També podrien incloure la força de fricció amb sentit contrari a la velocitat (figura 9). 


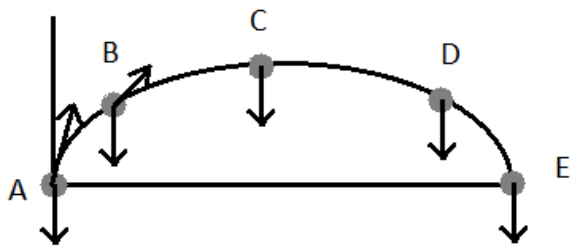

Figura 9. Forces sobre el coet

\section{d) Amb quina velocitat sortirà propulsat el coet?}

Si apliquem el principi de conservació de la quantitat de moviment (considerant menyspreable la massa d'aire expulsada).

- $\mathrm{m}_{\mathrm{c}}=$ Massa del coet

- $\mathrm{v}_{\mathrm{c}}=$ Velocitat a la que surt propulsat el coet

- $\mathrm{m}_{\mathrm{a}}=$ Massa expulsada d'aigua

- $\mathrm{v}_{\mathrm{a}}=$ Velocitat d'expulsió de l'aigua

$$
\begin{gathered}
\mathrm{m}_{\mathrm{c}} \cdot \mathrm{v}_{\mathrm{c}}-\mathrm{m}_{\mathrm{a}} \cdot \mathrm{v}_{\mathrm{a}}=0 \\
\mathrm{v}_{\mathrm{c}}=\frac{\mathrm{m}_{\mathrm{a}} \cdot \mathrm{v}_{\mathrm{a}}}{\mathrm{m}_{\mathrm{c}}}
\end{gathered}
$$

Aquest no és un plantejament totalment exacte, atès que la massa del coet no és constant, ja que va perdent aigua, no obstant això creiem que és suficient per als objectius d'aquest treball. Per altra banda s'ha de tenir en compte que conèixer la velocitat d'expulsió de l'aigua no és una dada necessària per desenvolupar la present experiència.

\section{e) Com es pot modificar la velocitat a la qual surt llançat el coet?}

Segons el resultat (1) influeixen la massa d'aigua, la massa del coet i la velocitat de sortida de l'aigua (que dependrà d'altres variables).

f) Raonar com creus que afectaran a la velocitat del coet els següents factors: massa del coet, massa de l'aigua i pressió de llançament.

Massa del coet: en principi segons l'expressió (1) a menor massa del coet, descomptant l'aigua, la velocitat aconseguida serà major, però alleugerir excessivament el cos del coet pot ser desfavorable pels següents motius:

Si s'eliminen les aletes o el llast davanter pot produir-se un vol inestable.

Un coet de molt poc pes tindrà major acceleració inicial, però també tindrà molt poca inèrcia quan hagi perdut l'aigua i el fregament de l'aire ho frenarà més fàcilment.
- Massa d'aigua: a major quantitat d'aigua, major serà el temps d'expulsió, major serà el temps de durada de la força impulsora sobre el coet i major la velocitat aconseguida en el coet. Però un excés d'aigua pot provocar que l'aire introduït sigui insuficient i no s'arribi a una pressió adequada o implicar major inèrcia i per tant menor acceleració.

- Pressió: en augmentar la pressió augmentarà la velocitat d'expulsió de l'aigua i segons 1) a major velocitat d'expulsió de l'aigua, major velocitat del coet.

No obstant això si plantegem la $2^{2}$ llei de la dinàmica al coet, suposada la seva massa constant:

- acceleració = força $/$ massa

- Tenint en compte que: velocitat = acceleració . temps durada de la força

- I la relació: pressió = força / superfície tap

Si reunim les tres expressions en la de la velocitat, quedaria l'expressió 2:

$$
\text { velocitat }=\frac{\text { pressió } \cdot \text { superficie tap }}{\text { massa }} \cdot \text { temps }
$$

Per tant segons (2) la velocitat aconseguida pel coet després de la impulsió (que dura menys d'un segon, mentre és expulsada l'aigua) és proporcional a la pressió aconseguida (la pressió realment representa la diferència de pressió entre l'interior i l'exterior de l'ampolla).

g) Si realitzéssim un llançament parabòlic, quines variables creus que influirien en l'abast horitzontal aconseguit?

Si els alumnes han estudiat el tir parabòlic, coneixen el model matemàtic obtingut a classe:

$$
\text { abast }=\frac{v_{\text {inicial coet }}^{2}}{g} \cdot \operatorname{sen} 2 \cdot a
$$

Com l'expulsió de l'aigua és rapidíssima, podem suposar que la velocitat aconseguida pel coet després de deixar anar tota l'aigua (2) és igual a la velocitat de sortida del tir parabòlic que figura en (3). Reunint 2 i 3:

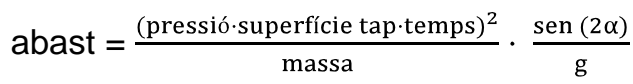

Si mantenim constants en els llançaments: la massa, superfície del tap, temps i angle i es va variant la pressió de llançament, quedarà (4):

$$
\text { abast }=\text { constant } \cdot \mathrm{p}^{2}
$$




\section{Recerca i resultats}

h) Proposar hipòtesis de com influeix la pressió del llançament en l'abast aconseguit. Realitzar diferents llancaments per contrastar les hipòtesis. Extreure conclusions.

Els alumnes solen plantejar que a major pressió, major serà l'abast. Solen representar abast enfront de pressió i sorprendre'ls no trobar una relació lineal. És fonamental que els alumnes exerceixin un adequat control de variables, aquelles que han de mantenir en el mateix valor durant totes les proves i que en el nostre cas serien:

- Coet utilitzat

- Quantitat d'aigua $=500 \mathrm{~mL}$

- Angle de llançament $=32 \circ$

- Massa del coet $=188 \mathrm{~g}$ (carcassa) $+90 \mathrm{~g}$ (contrapès)

La massa del coet serà la suma de la de la seva carcassa i del contrapès, però s'ha separat en les dues contribucions per facilitar així una possible reproducció de l'experiment. Els valors donats són els valors reals d'una de les experiències realitzades on es va mesurar l'abast aconseguit amb una corda llarga i la pressió del llançament amb el manòmetre de l'inflador, amb els resultats que presenta la figura 10.

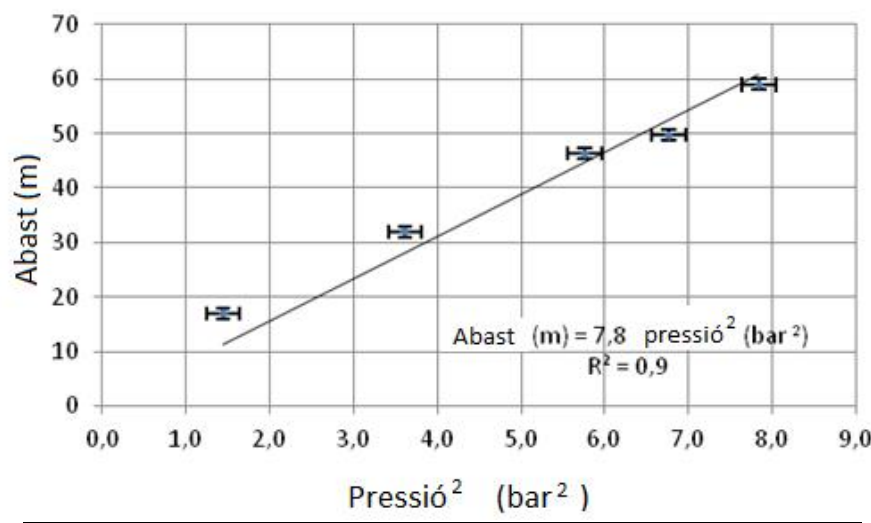

Figura 10. Abast enfront de pressió al quadrat

El resultat de la figura 10 no presenta una recta exacta que solament s'obtindria si es compliren totes les aproximacions realitzades: massa del coet constant, impulsió instantània. A més l'acceleració de frenat també és variable doncs depèn de la velocitat i per tant de la pressió de llançament i el fregament de l'aire depèn de la forma del coet i de diversos factors més (densitat de l'aire, posició del coet mentre puja...). El problema de la física del coet d'aigua no és en absolut senzill, atès que inclou moltes variables que en ocasions influeixen, fins i tot en sentits contraris.

\section{CONCLUSIONS}

Creiem que la proposta pot cobrir en gran manera els objectius proposats: treball col-laboratiu, aplicació del mètode científic i interessar i motivar a l'alumnat sobretot per l'espectacularitat de l'experiència. La proposta també permet aplicar les lleis estudiades en la pissarra de classe i contextualitzar algunes lleis fonamentals de la mecànica. Futurs treballs podrien estudiar l'efecte de la massa de l'aigua, massa del coet, angle de llançament, etc en l'abast aconseguit. No obstant això no podem deixar de dir que és una experiència que presenta dificultats i que comporta fracassos parcials que s'hauran de superar amb paciència i motivació.

\section{BIBLIOGRAFIA}

MARTÍNEZ, B. (2008) Anàlisi del moviment de coets d'aigua [article en línia]. Ciències, 11. [Data de consulta: 10 de març de 2013].

http://www.raco.cat/index.php/ciencies/article/downlo ad/123022/170772

NOBUAKI, I (2008). Coets d'aigua. Manual de l'educador [article en línia]. Organisme d'Exploració Aeroespacial de Japó. [Data de consulta: 27 d'abril de 2013].

https://2mp.conae.gov.ar/descargas/Materiales\%20 [1] /Cohetes_de_Agua-Manual_del_Educador.pdf

http://www.youtube.com/watch?v=S6OHCapmAFU\&featu re=youtu.be

[2] http://www.youtube.com/watch?v=ML4SQEcXMl8

Pàgines d'Internet amb informació teòrica sobre els coets d'aigua:

- http://4classes.blogspot.com.es/2010/03/cohetede-agua-prof-manuel-brito.html

- http://es.wikipedia.org/wiki/cohete_de_agua

- http://www.npl.co.uk/educate-explore/waterrocket-challenge/

- http://exploration.grc.nasa.gov/education/rocket/ rktbot.html

- http://www.ojocientifico.com/3639/el-cohete-deagua-un-experimento-divertido

\section{AGRAIMENTS}

A Trini Macià i a Rafael Colomer per la seva valuosa col-laboració. 